\title{
PENINGKATAN PERILAKU RELIGIUS MELALUI INTEGRASI PEMBELAJARAN PAI DAN PEMBINAAN DI UNIT KEGIATAN KEAGAMAAN MAHASISWA
}

\author{
Oleh: Syukri Fathudin AW. dan Sudiyatno
}

$$
\text { (FT - UNY) }
$$

Tujuan Penelitian ini untuk mengetahui 1) model pembinaan keagamaan di UNY; 2) mengetahui apakah ada perbedaan dalam berperilaku religius antara mahasiswa yang mengikuti pembelajaran PAI terpadu dengan mahasiswa yang mengikuti pembelajaran PAI; dan 3) mengetahui perilaku religius mahasiswa yang mengikuti perkuliahan Pendidikan Agama Islam yang terintegarasi dengan pembinaan di unit kegiatan keagamaan.

Penelitian ini adalah penelitian tindakan (action research). Subjek penelitiannya adalah mahasiswa Pendidikan Teknik Elektro Fakultas Teknik UNY kelas A. Objeknya adalah integrasi pembelajaran PAI dan pembinaan keagamaan mahasiswa melalui pelaksanaan program Tutorial Pendidikan Agama Islam.

Hasil yang bisa diperoleh adalah: 1) Model pembinaan keagamaan yang tepat untuk pembinaan keagamanaa melalui Tutorial Pendidikan Agama Islam adalah dengan strategi pembelajaran melalui diskusi dengan topik-topik kontemporer yang terjadi di masyarakat; 2) Hasil probabilitas 0,857>0,05 = Ho diterima. Tidak ada perbedaan yang signifikan dalam berperilaku religius antara mahasiswa yang mengikuti pembelajaran PAI terpadu dengan mahasiswa yang mengikuti pembelajaran PAI; dan 3) Perilaku religius mahasiswa yang mengikuti perkuliahan Pendidikan Agama Islam yang terintegrasi dengan pembinaan di unit kegiatan keagamaan pada umumnya, baik hal tersebut berdasar hasil ratarata amalan harian yaitu amalan Shalat fardlu dihasilkan rata-rata 3,78 maupun rata-rata amalan bacaan tilawah Al Qur'an yaitu 3,07.

\section{Pendahuluan}

Mahasiswa merupakan aset suatu bangsa yang sangat berharga. Mereka merupakan calon pemimpin dan penerus perjuangan bangsa. Manakala mahasiswa yang sekarang masih belajar di perguruan tinggi dapat terdidik secara utuh dan terarah, maka masa depan bangsa dan negara ini akan baik. Tetapi manakala mereka mendapatkan pendidikan yang parsial, hanya mementingkan sisi kecerdasan 
intelektual dan kekuatan fisik dan menyampingkan pembinaan kecerdasan intelektual dan spiritual, maka bangsa yang majemuk ini akan terancam keberlangsungannya.

Tantangan besar yang kedua harus dihadapi mahasiswa setelah lulus dan menjadi calon tenaga kerja di era sekarang tidak hanya pada tuntutan kemampuan pada aspek kecerdasan intelektual (kognitif) dan keterampilan fisik (skill), tetapi yang juga harus memiliki kecerdasan emosional dan spiritual yang kokoh. Hal ini dikarenakan tantangan permasalahan dalam kehidupan pribadi dan bermasyarakat semakin beragam dan semakin komplek. Oleh karena itu, dalam proses pembelajarannya, mahasiswa harus mendapatkan pembinaan yang baik agar kecerdasan emosional dan spiritualnya dapat berkembang optimal.

Salah satu aspek dalam diri mahasiswa yang harus dikembangkan dalam proses pendidikan adalah aspek afeksi (sikap, perilaku, dan kepribadian). Selama ini yang relatif banyak berkembang dan menjadi perhatian utama adalah pengembangan aspek kognisi dan psikomotorik. Hal ini tercermin pada jumlah jam mata kuliah pengembangan aspek-aspek ini yang harus ditempuh oleh mahasiswa selama masa studinya jauh lebih banyak dibandingkan dengan mata kuliah pengembangan aspek afeksi atau mata kuliah pengembangan kepribadian (MPK).

Dalam upaya mengembangkan kemampuan pada aspek afeksi, secara formal para mahasiswa diwajibkan mengikuti kuliah Pendidikan Agama Islam (PAI). Tujuan yang ingin dicapai dari perkuliahan ini adalah terbentuknya kepribadian yang baik pada mahasiswa yang beragama Islam. Secara khusus mahasiswa Muslim dapat mengikuti pembinaan keagamaan yang lebih intensif pada Tutorial Pendidikan Agama Islam. Pola integrasi ini menjadi penting karena pembinaan ketika kurang terkontrol dapat berdampak kepada perilaku keagamaan yang ekstrim.

Menurut Vita (2008: 10) banyak mahasiswa di DIY yang melakukan nikah sirri karena ketidakpahaman terhadap masalah agama. Mahasiswa yang mestinya berkembang menjadi pribadi unggul secara intelektual dan secara moral tergelincir mengikuti aliran sesat. Model integrasi antara pembelajaran formal (PAI) dengan pembinaan keagamaan khusus pada Tutorial Pendidikan Agama Islam membutuhkan strategi pembelajaran dan model penilaian yang tepat.

Pengaruh strategi penilaian hasil pembelajaran di kelas telah banyak diteliti dan telah memberikan kesimpulan bahwa melalui penerapan metode penilaian yang tepat telah memberikan pengaruh 
yang positif terhadap kinerja dan kepribadian siswa (Olina \& Sullivan, 2002: 61). Banyak faktor yang harus dipertimbangkan dalam memilih model penilaian yang efektif untuk suatu proses pembelajaran. Menurut Nitko (2007: 117) pembelajaran akan efektif ketika antara rencana pembelajaran (lesson plans), implementasi (teaching activities) dan sasaran pembelajaran (learning targets) kesemuanya berkesesuaian. Termasuk dalam rencana pembelajaran adalah rancangan penilaian yang akan digunakan.

Selama ini dominasi model penilaian konvensional (paper and pencil) telah menyebabkan pencapaian hasil pembelajaran PAI kurang optimal. Dikarenakan model penilaian ini hanya mampu mengukur pencapaian belajar pada aspek kognitif. Padahal diadakannya perkuliahan PAI dan menjadi mata kuliah wajib lulus bertujuan untuk membentuk agar mahasiswa memiliki kepribadian yang mulia, tidak hanya pada tingkat pemahaman tetapi harus sampai pada tingkat pengalaman dan membentuk sikap dan perilaku yang lebih permanen. Oleh karena itu, dibutuhkan model pembelajaran dan evaluasi yang tepat agar tujuan dari perkuliahan PAI dapat tercapai dengan optimal.

Dari latar belakang permasalahan di atas, penelitian ini akan mengungkap bagaimanakah model pembinaan di unit kegiatan keagamaan di UNY. Lebih jauh penelitian ini juga ingin mengungkap perbedaan yang ada dalam berperilaku religius antara mahasiswa yang mengikuti pembelajaran PAI terpadu dengan mahasiswa yang mengikuti pembelajaran PAI dan bagaimanakah perilaku religius mahasiswa yang mengikuti perkuliahan Pendidikan Agama Islam yang terintegarasi dengan pembinaan di unit kegiatan keagamaan.

\section{Pembelajaran Pendidikan Agama Islam}

Pendidikan adalah usaha sadar yang terus menerus untuk mewujudkan manusia yang unggul dalam ilmu pengetahuan dan anggun sikap moralnya adalah keniscayaan kita bersama. Dalam bait lagu kebangsaan kita yang dikarang WR. Supratman berbunyi “ bangunlah jiwanya - bangunlah badannya”, juga syair Mars UNY ciptaan Agus Untung pada bait yang terakhir ... mengemban tugas suci negara menuju cita-cita mulia galang cipta rasa karsa bagi nusa bangsa menjadi spirit bagi kita untuk membangun manusia yang sehat lahir dan batin, baik secara moral, intelektual, dan ketrampilan.

Pendidikan Agama Islam (PAI) adalah rumpun mata kuliah pengembangan kepribadian (MPK) dalam struktur mata kuliah umum (MKU) yang wajib lulus, dengan kode mata kuliah UNU 201. Dilihat 
dari posisinya PAI merupakan mata kuliah yang membekali peserta didik berupa kemampuan dasar tentang pemahaman, penghayatan dan pengalaman nilai-nilai dasar kemanusiaan, sebagai makhluk Allah, sebagai pribadi, anggota keluarga, masyarakat, warga negara, dan sebagai bagian dari alam.

Pendidikan Agama Islam di Perguruan Tinggi Umum (PTU) seperti halnya di Universitas Negeri Yogyakarta (UNY) berguna untuk membantu terbinanya mahasiswa yang beriman dan bertakwa kepada Allah SWT., berbudi pekerti luhur, berpikir filosofis, bersikap rasional dan dinamis, berpandangan luas ikut serta mewujudkan Indonesia yang utuh, aman, sejahtera yang diridhoi Allah SWT. Apabila dilihat dari nilai gunanya, nampaknya sungguh sangat indah dan ideal, tetapi jika dilihat dari proses pelaksanaannya, menimbulkan pertanyaan besar, mungkinkah merubah kepribadian, watak dan akhlak seseorang hanya dalam waktu satu semester? Sedangkan visi dan misinya sebagai berikut, visinya: menjadikan ajaran Islam sebagai sumber nilai, dan pedoman yang mengantarkan mahasiswa dalam mengembangkan profesi dan kepribadian Islami; misinya: terbinanya mahasiswa yang beriman, bertakwa, berilmu, dan berakhlak mulia, serta menjadikan ajaran Islam sebagai landasan berpikir dan berperilaku dalam pengembangan profesi.

\section{Proses pembelajaran}

Seiring dengan diberlakukan pembelajaran berbasis kompetensi yang meletakkan mahasiswa sebagai pusat belajar (student centered) maka dosen memosisikan diri sebagai fasilitator dan motivator. Dalam proses pembelajaran mestinya dikondisikan yang menyenangkan dan bermakna, karena yang disampaikan tidak saja pengetahuan melainkan pendidikan nilai-nilai kebenaran yang berasal dari Allah SWT. Ini dapat dimengerti karena Pendidikan Agama bukan saja digarap pada aspek kognisi-psikomotorik saja melainkan afeksi lebih dominan, karena afeksi atau sikap merupakan fungsi dari keyakinan. Seseorang yang yakin bahwa dengan melakukan perbuatan itu akan membawa dampak positif bagi dirinya maka ia akan bersikap untuk melakukan perbuatan tersebut. Sebaliknya jika perbuatan itu akan membawa dampak negatif bagi dirinya maka ia akan menunjukkan sikap untuk menolaknya. Keyakinan untuk berbuat sesuatu yang mendasari seseorang ini biasa dinamakan behavior belief. Atho' Mudzhar (1998: 3) menyatakan bahwa terdapat beberapa hal yang perlu dipikirkan dalam melaksanakan pembelajaran mata kuliah 
Pendidikan Agama Islam di perguruan tinggi umum, khususnya dari segi materi:

a. antara materi yang bersifat filosofis dan praktis;

b. antara penekanan akhlak (pembentukan kepribadian) dan ilmu pengetahuan; dan

c. antara keperluan mengaitkan agama dengan iptek dan memisahkan agama dari isu-isu iptek

\section{Tutorial Pendidikan Agama Islam (PAI)}

Tutorial PAI merupakan kegiatan khusus yang menekankan pada pendalaman dan penguasaan keterampilan praktek ibadah dan baca tulis al-Quran yang diwajibkan kepada mahasiswa yang mengambil mata kuliah Pendidikan Agama Islam. Kegiatan tutorial PAI ini relevan dengan model belajar cooperative learning, karena proses pembelajarannya diselenggarakan dalam kegiatan belajar mengajar tutorial (KBMT). Tutor berasal dari teman sebaya, artinya dilakukan dengan prinsip belajar bersama (Syukri, 2006: 16).

Pada perkembangan selanjutnya tutorial PAI merupakan sarana menyebarkan nilai-nilai Islam yang bertujuan untuk memberikan pendalaman dan penguasaan tambahan keislaman bagi mahasiswa di luar materi perkuliahan Pendidikan Agama Islam. Dengan tutorial PAI diharapkan terbentuk sosok pribadi Muslim yang utuh, tangguh, menjadi suri tauladan dan sanggup menyebarkan Dakwah Islam (Agent of Change and Inovation) kepada warga kampus maupun masyarakat umum.

Kedudukan dan status tutorial Pendidikan Agama Islam di UNY adalah:

a. Wajib diikuti oleh seluruh mahasiswa UNY yang mengambil mata kuliah Pendidikan Agama Islam.

b. Merupakan pendukung mata kuliah PAI yang dimaksudkan untuk pendalaman atau perluasan materi PAI dan aspek ibadah

c. Mahasiswa yang telah mengikuti tutorial PAI dengan ketentuan pertemuan kegiatan belajar mengajar tutorial (KBMT) dan mengikuti kuliah akhir semester atau pesantren sehari akan mendapatkan nilai akhir tutorial.

d. Kedudukan nilai akhir tutorial PAI adalah sebagai nilai yang ikut dipertimbangkan dalam penentuan nilai akhir mata kuliah PAI oleh dosen pengampu PAI. 


\section{Cara Penelitian}

Penelitian yang dipilih dalam rangka mengembangkan model pembelajaran terpadu antara PAI dan pembinaan keagamaan bagi mahasiswa UNY, khususnya melalui tutorial Pendidikan Agama Islam, adalah penelitian tindakan (action research). Penelitian tindakan ini menitikberatkan upaya untuk meningkatkan kualitas subjek penelitian. Atau pada prosesnya berusaha untuk menemukan langkah-langkah yang tepat dalam menyelenggarakan suatu program, sehingga program tersebut menjadi lebih efektif. Pada penelitian tindakan ini pelaksana (pendidik) juga berlaku sebagai peneliti dan merupakan kunci utama keberhasilan penelitian (Sukardi, 2003: 211).

Pelaksanaan penelitian ini pada tahun akademik 2008/2009 selama satu semester di semester gasal. Penelitian ini mengambil tempat di Jurusan Pendidikan Teknik Elektro, Fakultas Teknik, Universitas Negeri Yogyakarta.

Dalam penelitian ini yang menjadi subjek penelitian adalah mahasiswa Jurusan Pendidikan Teknik Elektro yang mengikuti perkuliahan Pendidikan Agama Islam di semester gasal. Jumlah populasi mahasiswa baru ini terdiri atas mahasiswa program reguler dan non reguler berjumlah 72 mahasiswa yang terbagi dalam 2 kelas reguler dan nonreguler. Sampel penelitian dipilih satu kelas sebagai kelompok perlakuan yang akan mendapatkan pembelajaran secara terpadu antara PAI dan pembinaan keagamaan di unit kegiatan mahasiswa melalui tutorial Pendidikan Agama Islam, serta kelompok pembanding.

Teknik analisis yang digunakan pada penelitian ini adalah teknik analisis deskriptif kualitatif yang berupa laporan dari kejadiankejadian selama proses penelitian, analisis, refleksi, dan rekomendasi serta kesimpulan mulai dari perencanaan sampai dengan dinyatakannya selesai dari siklus penelitian yang dilakukan. Deskripsi tentang catatan harian (diaries), profil pembelajaran (lesson profile), dan kinerja subjek penelitian (samples of children's work) akan dilengkapi dengan hasil penilaian diri dan penilaian teman sekelompoknya.

Penilaian pada penelitian tindakan berdasarkan kriteria yang ditentukan oleh peneliti dan akan dimintakan pertimbangan kepada beberapa dosen PAI yang telah berpengalaman. Kriteria utamanya adalah penggunaan kosa kata selama pengajaran mikro berlangsung. Kriteria keberhasilannya adalah jika para mahasiswa telah cukup 
terampil dalam menggunakan format penilaian diri (self assessment) dan format penilaian teman sekelompoknya (peer assessment).

Siklus dalam penelitian tindakan ini direncanakan sebanyak 3 siklus. Masing-masing siklus terdiri atas 3 kegiatan tatap muka. Jika selama tiga siklus kriteria keberhasilan belum tercapai, maka akan diteruskan dengan siklus berikutnya sampai kriteria yang ditentukan tercapai. Untuk mendapatkan hasil pengukuran yang valid, dilakukan triangulasi dengan beberapa jenis sumber data, di antaranya dari catatan harian, hasil kerja siswa, hasil penilaian, dan hasil observasi langsung.

\section{Hasil Penelitian dan Pembahasan}

Penelitian ini dilakukan terhadap 27 mahasiswa Pendidikan Teknik Elektro Fakultas Teknik UNY kelas A (reguler) sebagai responden. Peneliti mengembangkan model integrasi pembelajaran PAI dan pembinaan keagamaan mahasiswa melalui pelaksanaan program Tutorial Pendidikan Agama Islam. Berdasarkan model penelitian tindakan kelas (PTK) yang dikembangkan oleh Elliot (1993: 77) hasilnya dapat dipaparkan sebagai berikut:

\section{Riwayat pendidikan}

Berdasar tes penjajagan diawal perkuliahan PAI diketahui riwayat pendidikan sbb:

\begin{tabular}{|cc|cc|lcc|}
\hline \multicolumn{2}{|c|}{ Sekolah Dasar } & \multicolumn{3}{|c|}{ SLTP } & \multicolumn{3}{c|}{ SLTA } \\
\hline SD & MI & SMP & MTS & SMA & MA & SMK \\
\hline 23 & 4 & 24 & 3 & 16 & 2 & 9 \\
\hline
\end{tabular}

Dari data riwayat pendidikan di atas dapat dinilai bahwa kebanyakan mahasiswa (responden) berasal dari sekolah umum, artinya mereka hanya mendapatkan mata pelajaran Pendidikan Agama Islam tiap pekan 2 jam.

\section{Organisasi keagamaan}

Aktivitas keagamaan melalui organisasi keagamaan yang dilakukan responden selama ini diketahui sbb:

\begin{tabular}{|l|l|c|}
\hline No. & Organisasi Keagamaan & Jumlah/Orang \\
\hline 1. & Remaja Masjid & 6 \\
\hline
\end{tabular}




\section{$2 . \quad$ Majelis Taklim}

1

Dari data keaktifan pada organisasi keagamaan diperoleh hasil keaktifan responden pada organisasi keagamaan sangat kurang.

\section{Prestasi di bidang keagamaan}

Adapun prestasi di bidang keagamaan yang pernah diikuti oleh responden selama ini dapat diketahui sbb:

\begin{tabular}{|l|l|c|}
\hline No. & Jenis perlombaan & Jumlah/Orang \\
\hline 1. & Cerdas Cermat Al Qur'an & 1 \\
\hline
\end{tabular}

Dari data prestasi di bidang keagamaan dapat diketahui bahwa partisipasi responden pada event-event keagamaan baik MTQ maupun porseni sangat rendah.

\section{Intensitas ibadah}

Intensitas ibadan yang dilakukan responden selama ini dapat diketahui sbb:

\begin{tabular}{|l|l|c|c|c|}
\hline No. & \multicolumn{1}{|c|}{ Jenis ibadah } & a (tinggi) & b (sedang) & c (rendah) \\
\hline 1. & Shalat wajib & 21 & 6 & \\
\hline 2. & $\begin{array}{l}\text { Shalat berjamaah } \\
\text { di masjid }\end{array}$ & 2 & 24 & 1 \\
\hline 3. & $\begin{array}{l}\text { Shalat Sunnah } \\
\text { Rawatib }\end{array}$ & 2 & 24 & 1 \\
\hline 4. & Shalat Tahadjud & & 24 & 3 \\
\hline 5. & Tilawah Qur'an & 1 & 22 & 4 \\
\hline 6. & $\begin{array}{l}\text { Keaktifan } \\
\text { pengajian }\end{array}$ & 3 & 8 & 16 \\
\hline
\end{tabular}

Berdasar data dari keseluruhan tabel diatas maka melalui pembelajaran PAI di kelas dan pembinaan keagamaan khususnya melalui tutorial PAI diharapakan responden mampu meningkatkan intensitas ibadah, harapannya perolehan bagian b ( sedang) dan c (rendah) dapat ditiadakan atau minimal dikurangi.

\section{Hasil catatan harian (diaries/mutaba'ah)}

Penelitian ini dilakukan terhadap 28 mahasiswa Pendidikan Teknik Elektro Fakultas Teknik UNY kelas A sebagai responden. Dari 
28 mahasiswa dibagi menjadi 3 kelompok. Berikut pembagian kelompok tutorial:

\begin{tabular}{|l|l|l|l|}
\hline No. & Nama Kelompok & Jumlah Peserta & Nama Tutor \\
\hline 1. & Kelompok I & 10 orang & Catur Slamet \\
\hline 2. & Kelompok II & 11 orang & Muarif \\
\hline 3. & Kelompok III & 6 orang & Miftahul Jana \\
\hline
\end{tabular}

Catatan harian digunakan untuk mengetahui kemajuan peningkatan perilaku religius mahasiswa. Metode yang digunakan oleh para tutor sebagian besar tanya jawab dan diskusi tentang masalah-masalah keagamaan kontemporer yang terjadi di masyarakat. Berikut dapat disampaikan hasil tanya jawab dan diskusi tutorial:

- masalah pernikahan (munakahat) baik syarat, rukun, maupun poligami dan pernihan dini,

- masalah terorisme dan jihad fi sabililah, dan

- aliran-aliran sesat dan menyimpang dari Dinul Islam.

\section{Pola pembinaan keagamaan melalui tutorial}

Tutorial PAI merupakan kegiatan khusus yang menekankan pada pendalaman dan penguasaan keterampilan praktek ibadah dan baca tulis al-Quran yang diwajibkan kepada mahasiswa yang mengambil mata kuliah Pendidikan Agama Islam. Kegiatan tutorial PAI ini relevan dengan model belajar cooperative learning, karena proses pembelajarannya diselenggarakan dalam kegiatan belajar mengajar tutorial (KBMT). Tutor berasal dari teman sebaya, artinya dilakukan dengan prinsip belajar bersama (Syukri, 2006: 16).

Pada perkembangan selanjutnya tutorial PAI merupakan sarana menyebarkan nilai-nilai Islam yang bertujuan untuk memberikan pendalaman dan penguasaan tambahan keislaman bagi mahasiswa di luar materi perkuliahan Pendidikan Agama Islam. Dengan tutorial PAI diharapkan terbentuk sosok pribadi Muslim yang utuh, tangguh, menjadi suri tauladan, dan sanggup menyebarkan dakwah Islam (agent of change and inovation) kepada warga kampus maupun masyarakat umum.

Adapun alur kegiatan tutorial PAI di UNY dapat dilihat pada matrik berikut ini:

Peningkatan Perilaku Religius melalui Integrasi Pembelajaran PAI dan 


\begin{tabular}{|l|l|}
\hline No. & \multicolumn{1}{|c|}{ Nama Kegiatan } \\
\hline 1. & Orientasi Tutorial \\
\hline 2. & Kegiatan Belajar Mengajar Tutorial ( KBMT) \\
\hline 3. & Pesantren Seharí \\
\hline 4. & Ujian Mid Tutorial \\
\hline 5. & Ujian Akhir Tutorial \\
\hline
\end{tabular}

Perilaku religius mahasiswa yang mengikuti pembelajaran PAI dan pembinaan keagamaan secara integratif melalui tutorial PAI

Proses perkuliahan Pendidikan Agama Islam (PAI) di jurusan Pendidikan Teknik Elektro telah dilaksanakan 16 x kuliah tatap muka. Dari tugas-tugas yang telah diberikan dan pengamatan oleh dosen PAI tentang perilaku religius mereka, kecenderungan mereka dapat dikelompokkan menjadi tiga kelompok, rajin beribadah, kurang aktif dalam beribadah, dan pasif dalam ibadah.

Sedangkan target pembinaan keagamaan mahasiswa melalui tutorial PAI dapat dijelaskan melalui matrik sbb.:

\begin{tabular}{|c|l|l|}
\hline No. & \multicolumn{1}{|c|}{ Jenis Amalan } & \multicolumn{1}{c|}{ Target } \\
\hline 1. & Shalat Fardlu & 5 x sehari \\
\hline 2. & Shalat Berjama'ah & $3 \times$ sepekan \\
\hline 3. & Shalat sunnah rawatib & $3 \times$ sepekan \\
\hline 4. & Shalat Dluha & $1 \times$ sepekan \\
\hline 5. & Puasa Sunnah & $2 \times$ sebulan \\
\hline 6. & Tilawah Qur'an & $1 \times$ sehari \\
\hline 7. & Shalat Malam & 2 x sepekan \\
\hline
\end{tabular}

Skor monitoring amalan harian (7 jenis amalan), dengan menggunakan skala sbb:

- Tidak / jarang

$1-1,75$

- Kadang-kadang

$1,8-2,7$

- Sering

$2,8-3,7$

- Selalu

$3,8-4$

Adapun rincian hasil amalan sbb.:

\begin{tabular}{|c|l|c|c|}
\hline No. & Jenis Amalan & Hasil & Skor Rata-rata \\
\hline 1. & Shalat Fardlu & $102 / 27$ & 3,78 \\
\hline 2. & Shalat Jamaaah & $80 / 27$ & 2,96 \\
\hline 3. & Shalat Sunnah Rawatib & $52 / 27$ & 1,93 \\
\hline
\end{tabular}




\begin{tabular}{|c|l|c|c|}
\hline 4. & Shalat Dhuha & $60 / 27$ & 2,22 \\
\hline 5. & Puasa Sunnah & $62 / 27$ & 2,29 \\
\hline 6. & Tilawah Qur'an & $83 / 27$ & 3,07 \\
\hline 7. & Shalat Malam & $60 / 27$ & 2,22 \\
\hline
\end{tabular}

[DataSet2] D:luji-t-1.sav

T-TEST

Group Statistics

\begin{tabular}{|ll|r|r|r|r|}
\hline & PAI & $\mathrm{N}$ & Mean & $\begin{array}{c}\text { Std. } \\
\text { Deviation }\end{array}$ & $\begin{array}{c}\text { Std. Error } \\
\text { Mean }\end{array}$ \\
\hline Mid & Perlakuan & 30 & 76.667 & 3.3045 & .6033 \\
& Pembanding & 37 & 74.324 & 3.5672 & .5865 \\
\hline
\end{tabular}

Independent Samples Test

\begin{tabular}{|c|c|c|c|c|}
\hline & \multicolumn{2}{|c|}{ Mid } \\
\hline & & & $\begin{array}{l}\text { Equal } \\
\text { variances } \\
\text { assumed }\end{array}$ & $\begin{array}{l}\text { Equal } \\
\text { variances } \\
\text { not } \\
\text { assumed }\end{array}$ \\
\hline $\begin{array}{l}\text { Levene's Test for } \\
\text { Equality of } \\
\text { Variances }\end{array}$ & $\begin{array}{l}\text { F } \\
\text { Sig. }\end{array}$ & & $\begin{array}{l}.033 \\
.857\end{array}$ & \\
\hline t-test for Equality & $\mathrm{T}$ & & 2.761 & 2.784 \\
\hline of Means & Df & & 65 & 63.806 \\
\hline & Sig. (2-tailed) & & .007 & .007 \\
\hline & Mean Difference & & 2.3423 & 2.3423 \\
\hline & Std. Error Differenc & & .8482 & .8414 \\
\hline & $95 \%$ Confidence & Lower & .6483 & .6614 \\
\hline & $\begin{array}{l}\text { Interval of the } \\
\text { Difference }\end{array}$ & Upper & 4.0363 & 4.0233 \\
\hline
\end{tabular}

Ho = Antara rata-rata nilai ujian mid semester kelompok perlakuan dengan rata-rata nilai ujian mid kelompok pembanding tidak berbeda. $\mathrm{H} 1=\mu 1 \neq \mu 0$

Peningkatan Perilaku Religius melalui Integrasi Pembelajaran PAI dan

Pembinaan di Unit Kegiatan Keagamaan Mahasiswa (Syukri Fathudin AW. dan Sudiyatno) 
Ho diterima $\mathrm{P}>0,05 \mathrm{H} 1$ ditolak

Ho diterima $\mathrm{P}<0,05 \mathrm{H} 1$ diterima

Probabilitas 0,857>0,05 jadi Ho diterima

Artinya: Nilai Rata-rata ujian mid semester Kelompok Perlakuan dibanding Nilai Rata-rata Kelompok Pembanding tidak berbeda secara signifikan.

\section{Kesimpulan}

Berdasarkan data hasil penelitian dan pembahasannya dapat disimpulkan sebagai berikut:

1. Model pembinaan keagamaan yang tepat dilakukan untuk pembinaan keagamanaa adalah melalui tutorial Pendidikan Agama Islam, dengan strategi pembelajaran melalui diskusi dengan topiktopik kontemporer yang terjadi dimasyarakat.

2. Hasil probabilitas $0,857>0,05=$ Ho diterima. Tidak ada perbedaan yang signifikan dalam berperilaku religius antara mahasiswa yang mengikuti pembelajaran PAI terpadu dengan mahasiswa yang mengikuti pembelajaran PAI.

3. Perilaku religius mahasiswa yang mengikuti perkuliahan Pendidikan Agama Islam yang terintegarasi dengan pembinaan di unit kegiatan keagamaan pada umumnya baik. Hal tersebut berdasar hasil rata- rata amalan harian, yaitu amalan shalat fardlu dihasilkan rata-rata 3,78 dan rata-rata amalan bacaan tilawah al Quran, yaitu 3,07.

\section{Daftar Pustaka}

Ari Ginanjar Agustian. (2005). Rahasia Sukses membangun kecerdasan emosi dan spiritual(ESQ). Jakarta: Arga.

Atho Mudzhar. (1998). "Visi dan Misi Pendidikan Agama Islam pada Perguruan Tingggi Umum". Jurnal Studi Islam MUKADDIMAH., Yogyakarta: Kopertais III.

Chaves, J.F, Baker, CM, Chaves , J.A \& Fisher .M.L. (2006). "Self, Peer and tutor assessments os MSN competencies using the PBL- evaluator". Journal of Nursing Education Vol 45 No.1, pp 25-31 diambil 17 Maret 2008, dari http: // proquest umi.com/pqdweb. 
Elliot, J. (1993). Action Research for education change. Philadelphia: t.p.

Malik Fadjar, Abdul. (1998). Visi Pembaruan Pendidikan Islam. Jakarta: LP3NI.

Nitko, A.J., \& Brookhart, S.M. (2007). Educational Assessment of Students, Fifth Edition. Ohio: Pearson Prentice Hall.

Olina, Z. \& Sullivan, H.J. (2002). Effects of classroom evaluation strategies on student achievement and attitudes. Educational Technology, Research and Development. Vol. 50, No. 3. pp. 6175.

Pardjono dan Wardan Suyanto. "Kurikulum Berbasis Kompetensi, Konsep dan Implementasi”. Makalah Seminar dan Lokakarya Implementasi KBK di FT UNY, 11 - 12 Agustus 2003.

Popham, W.J.. (1995). Classroom assessment: what teachers need to know, Boston-USA: Ally and Bacon.

Sarbiran. (2002). "Optimalisasi dan Implementasi Peran Pendidikan Kejuruan dalam Era Desentralisasi Pendididikan". Pidato Dies XXXVIII Universitas Negeri Yogyakarta 21 Mei 2002, Yogyakarta: Universitas Negeri Yogyakara.

Sivan, A .(2000). The implementation of peer assessmment: An action research approach, Assessment in education, Vol. 7 No.2, pp 193 - 213, diambil pada 10 Februari 2008, dari http: //proquest.umi.com/pdqweb.

Sudjana. (1992). Metoda Statistika. Edisi 5, Bandung: Tarsito.

Sukardi. (2003). Metodologi Penelitian Pendidikan, Kompetensi dan Prakteknya. Jakarta: Bumi Aksara.

Sumarno. (2008). "Model Pembelajaran Pendidikan Agama Islam berdasarkan Contextual and Teaching (CTL)". Makalah Diskusi Dosen dan Tutor Pendidikan Agama Islam, 14 Februari 2008. 
Syukri Fathudin. (2005). "Peningkatan mutu pembelajaran Pendidikan Agama Islam melalui Kurikulum Bebasis Kompetensi”. Jurnal Humanika, UPT MKU UNY Yogyakarta.

. (2006). "Menerapkan metode cooperative learning dalam pembelajaran Pendidikan Agama Islam". Jurnal Humanika, UPT MKU UNY Yogyakarta.

Tim Dosen PAI UNY. (2002). Dien Al Islam. Yogyakarta: UNY Press.

Vita Fitria. (2008). "Nikah Sirri dan problematikanya bagi perempuan", Laporan Penelitian Kajian Wanita. Jakarta: Dikti Depdiknas.

\section{Biodata Penulis}

1. Syukri Fathudin Achmad Widodo, dilahirkan di Kab.Semarang pada 12 Maret 1975, menyelesaikan sarjana pada STAIN Salatiga dan pascasarjana pada UNNES Semarang, saat ini berkarya sebagai pengajar pada jurusan Pendidikan Teknik Mesin FT UNY dan unit MKU UNY.

2. Sudiyatno, dilahirkan di Banyumas, 6 September 1965, menyelesaikan sarjana pada jurusan Pendidikan Teknik Mesin FKT IKIP Yogyakarta dan S2 pada Master Engenering Aucland of University New Zealand dan S3 pada jurusan Penelitian dan Evaluasi Pendidikan PPs UNY ( proses penelitian studi akhir). Sehari-hari berkarya sebagai pengajar pada jurusan Pendidikan Teknik Mesin FT UNY. 